\title{
CONHECIMENTO PRÉVIO, METACOGNIÇÃO E LEITURA - COMO OS ALUNOS ACIONAM AS INFORMAÇÕES NAS ATIVIDADES DO LIVRO DIDÁTICO?
}

Patricia Ferreira Botelho (UGB, UFRJ)

Resumo: Esse trabalho discute a qualidade das atividades escolares de leitura de livros didáticos, sabendo-se que essa atividade é largamente requerida no ambiente escolar. É fato que os alunos, enquanto leem, acessam o seu conhecimento prévio para constituir noções que lhes permitam tentar compreender um dado texto. $O$ uso consciente do conhecimento prévio em leitura é uma estratégia metacognitiva, porque leva em conta a capacidade da pessoa em monitorar e regular suas atividades cognitivas, potencializando o trabalho da mente requerido em atividades escolares. Acreditamos que um estudo com conceitos caros a essa teoria mostrará claramente a influência do conhecimento prévio do aluno no desenvolvimento de atividades de leitura. Em via de discutir e apontar soluções para os problemas relacionados à exploração ineficiente do conhecimento prévio nas atividades de leitura nos livros didáticos, realizamos um estudo comparativo entre as perguntas de interpretação de texto presentes no livro didático empregado no sexto ano da rede municipal de ensino e novas perguntas formuladas por nós para um teste de leitura com o mesmo texto, mas em turma diferente; essas perguntas consideram o conhecimento prévio do aluno sobre o assunto abordado e o ajudam a explorá-lo. O cotejo entre as atividades do livro e as elaboradas por nós objetiva verificar como se pode alcançar a melhoria da qualidade de leitura na escola, avaliar que tipos de estratégias de acesso ao conhecimento prévio podem viabilizar essa melhoria e comparar o saber do aluno envolvido na compreensão do que lê, em relação aos objetivos traçados pelos materiais didáticos. Palavras-chave: Conhecimento prévio; Metacognição; Ensino de leitura.

Abstract: This paper discusses the quality of school activities from reading textbooks, knowing that this activity is widely applied in the school environment. It is a fact that students, as they read, access their prior knowledge to build notions that allow them to try to understand 
a given text. The conscious use of prior knowledge in reading is a metacognitive strategy because it takes into account a person's ability to monitor and regulate their cognitive activities, enhancing the work of mind required for school activities. We believe that a study with friendly concepts of this theory clearly show the influence of prior knowledge of the student in the development of reading activities. In the process of discussing and pointing out solutions to the problems related to inefficient exploration of prior knowledge in reading activities in textbooks, we conducted a comparative study of the reading comprehension questions present in textbooks applied in the sixth year of municipal schools and new questions raised by us to a reading test with the same text, but in a different class; these questions consider prior knowledge of the student on the subject matter, and help him/ her to explore it. The collating between the book activities and the elaborated by us aims to verify how one can achieve improved reading quality in school, evaluate what types of access strategies to prior knowledge can enable this improvement and compare the knowledge of the student involved in understanding of reading, concerning the goals set by the teaching materials.

Keywords: Prior knowledge; Metacognition; Teaching reading.

\section{INTRODUÇÃO}

A capacidade de autojulgamento e de autorreflexão para escolhas e decisões é tida por estudiosos como Tomasello \& Rakoczy (2003) como recurso cognitivo que nos distingue de outros primatas. Por isso, quando interagimos em sociedade, somos capazes de compreender nossas escolhas linguísticas e nos orientar por meio de nossas intenções.

Além disso, a escola se constitui como um espaço social pleno, que pode propiciar ações de reflexão sobre a nossa linguagem. Monitoramos nossa postura social; organizamos 
nosso pensamento e nossos estudos, adequando-os aos nossos objetivos; reestruturamos nossa postura, de acordo com a exigência de cada ambiente etc. Essas ações são possibilitadas devido à capacidade de reflexão humana sobre os próprios processos cognitivos. Esse autoconhecimento, ou seja, esse processo de administração que uma pessoa tem da sua cognição é denominado metacognição, uma área de estudos, que ganhou força na década de 70, quando Flavell definiu o termo metacognição, e se desenvolveu intensamente nas décadas subsequentes (SCHNEIDER \& LOCKL, 2002).

Este trabalho enfoca a atividade de leitura no ambiente escolar, considerando-se aspectos do livro didático e o conhecimento do aluno no acesso aos textos, buscando revelar o crescimento dos estudos em metacognição e destacar sua importância em atividades escolares. Sabe-se que o papel do livro didático seria a promoção de atividades que auxiliem o aluno no desenvolvimento da leitura, fazendo uso de seu conhecimento prévio para construir significados e para ter ações autônomas como leitores. Entretanto, esse fazer não tem sido propiciado nesses materiais, o que permite a este estudo promover uma avaliação sobre como se tem desenvolvido a leitura no ambiente escolar e verificar meios de repensar essa atividade, utilizando-se conceitos e estratégias relacionados aos estudos em metacognição. 
Num primeiro momento, este trabalho se propõe a avaliar o conceito de metacognição, para, em seguida, apresentar questões relevantes a um estudo que relacione essa área aos processos de aprendizagem, sobretudo em leitura. A parte final desse trabalho é composta pela análise de um teste, já aplicado, que permitiu avaliar uma atividade de leitura desenvolvida por estudantes, mostrando a importância do uso de estratégias metacognitivas para a compreensão textual.

\section{FUNDAMENTAÇÃO TEÓRICA}

A pesquisa em metacognição, que investiga o conhecimento sobre a cognição, e a assunção de estudos que consideram esse atributo como uma realidade psicológica, iniciou-se na década de 70 por Brown, Flavell e outros (BROWN et al Apud SCHNEIDER \& LOCKL, 2002, p. 224), voltados para o conhecimento sobre memória, criando-se o termo metamemória que, em seguida, ampliou-se para dar origem ao termo metacognição. Nesse momento, a metacognição era definida como qualquer conhecimento ou atividade que tem como objeto cognitivo aspectos quaisquer de atividade cognitiva.

Outra linha de estudos, no início da década de 80, focava o conhecimento de crianças sobre o mundo mental - Teoria da Mente. Um segmento de estudos relacionados 
a essa pesquisa pode ser associado à metacognição porque considera a compreensão da criança sobre seus próprios processos mentais e as diferentes fases de desenvolvimento da compreensão.

Essas diferentes linhas de estudos, inicialmente, apresentavam certa impossibilidade em promover associações, pois, por um lado, os pesquisadores da década de 70 focavam o conhecimento voltado para a execução de tarefase para as definições da própria mente; e, por outrolado, os da década de 80 estabeleceram-se sobre o conhecimento voltado para as descobertas da mente, focando desejos e intenções, e da mente do outro (SCHNEIDER \& LOCKL, 2002).

O hiato que havia entre essas correntes de estudos foi, depois, desfeito por Kuhn em 2000, que apresentou uma estrutura conceptual que permitiu associá-las - o metaconhecimento (SCHNEIDER \& LOCKL, 2002), um saber que envolve tanto a compreensão relativa à execução de tarefas e da própria mente como também a percepção de desejos e intenções, constituindo as bases para o que concebemos como conhecimento metacognitivo.

A junção desses dois campos de estudo, já iniciada com a apresentação do conceito de metaconhecimento, permite definir a metacognição como a capacidade humana 
de monitorar e de autorregular os processos cognitivos, apresentando, também, os dois diferentes movimentos que a compõem: o monitoramento e o controle (NELSON \& NARENS, 1990), como podemos perceber na figura a seguir.
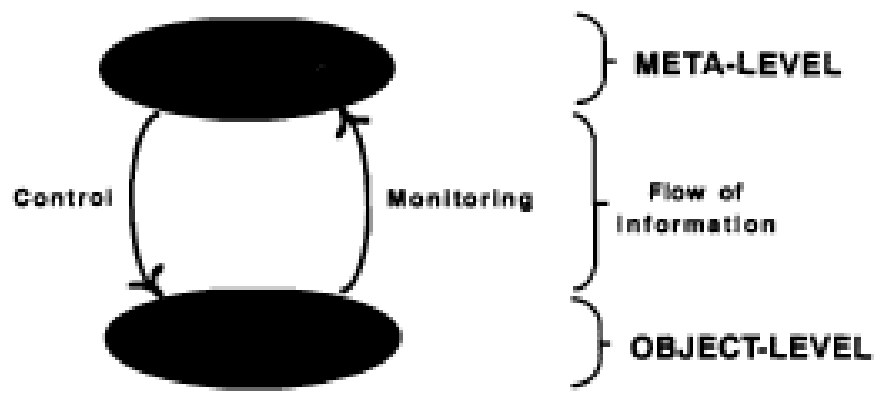

Figura 1 - O monitoramento e o controle metacognitivo (NELSON \& NARENS, 1990, p.126)

O monitoramento metacognitivo relaciona-se à postulação de hipóteses sobre o trabalho cognitivo, como os julgamentos que se faz acerca da facilidade ou dificuldade no aprendizado sobre um dado. Trata também do nível de confiança que se desenvolve na busca por uma informação, com a recuperação ou a retrospecção a um dado. O controle metacognitivo volta-se para a definição de objetivos que propiciem a aprendizagem ou o conhecimento cognitivo. Desse modo, o controle pode relacionar-se à seleção de estratégias que viabilizem o aprendizado, e sua ação pode ser requerida até durante o fluxo cognitivo.

Para tanto, vale ressaltar que desenvolver atividades com consciência metacognitiva exige a percepção de que há 
dois planos de conhecimento: um plano do objeto, em que determinada atividade se processa; e um plano meta, em que ocorrem as suas condições de validação, administrando a cognição durante esse processo (NELSON \& NARENS, 1990; GERHARDT, 2009). Isso referenda a importância do desenvolvimento da leitura como um aprendizado autorregulado e a necessidade de oferecer atividades de leitura que enfoquem esse tipo de aprendizado.

Destarte, a conscientização da estratégia metacognitiva utilizada para ler, ou aprender uma dada atividade, auxilia no processo de compreensão. Cabe, aqui, a seguinte pergunta: $\mathrm{O}$ que explorar em leitura? Em resposta a isso, pode-se dizer que se deve privilegiar o conhecimento prévio do aluno e o contexto em que se aplica o material a ser lido. Há, assim, no desenvolvimento da atividade de leitura, a exigência de dois saberes básicos: saber como acessar o conhecimento prévio, e saber como associar essa informação ao que está sendo lido.

Retomando Griffith \& Ruan (2005), há alguns requisitos fundamentais ao que deve ser explorado em leitura, tornando-a hábil:

1. A construção da estrutura organizacional do texto, ou seja, a coerência, num nível macrotextual; 
2. A busca pelo sentido denotado pelas ideias presentes na estrutura gramatical do texto, num nível microtextual;

3. A interação entre esses níveis textuais e o conhecimento prévio do leitor;

4. A interação entre os dois processos cognitivos básicos de processamento da informação denominados ascendente (movimento que explora o conhecimento prévio) e descendente (movimento que recruta as informações do texto).

O desenvolvimento desta leitura hábil é constituído, também, pela aplicabilidade de saberes metacognitivos, destacados em Griffith \& Ruan (2005). Essa aplicabilidade abrange, da mesma forma, a regulação da cognição objetivando a resolução de problemas presentes no fluxo da leitura: a flexibilização de hipóteses feitas sobre o material, e a avaliação da eficácia das ações cognitivas e das estratégias adotadas.

A partir dessas notações, pode-se postular que o sucesso na atividade de leitura depende do uso de estratégias metacognitivas. Assim, uma leitura estratégica demonstra adequação a contextos e revela a escolha de diferentes técnicas e habilidades com o fim de atingir determinado resultado. Além disso, essa atividade exige o monitoramento contínuo para alcançar um desenvolvimento eficiente. A explicitação e o uso contínuo de estratégias metacognitivas 
em leitura permitem constituir um leitor maduro e hábil, tornando-o consciente em aplicar estratégias que, com o uso, se automatizam.

Vale ressaltar que, embora haja largos estudos que investigam meios para o desenvolvimento eficaz da leitura, sabe-se que o ensino dessa atividade no ambiente escolar não tem sido efetivado com sucesso. Com fins de verificar como este estado de coisas pode ser melhorado, e considerando os saberes aqui descritos buscando alcançar estratégias válidas para o ensino de leitura, chega-se à necessidade de avaliação dessa atividade desenvolvida efetivamente em sala de aula por meio de um teste, já aplicado para este estudo, que será largamente abordado nas seções seguintes.

\section{METODOLOGIA}

Sabe-se que a leitura é uma atividade fundamental para a construção do conhecimento dos alunos e permeia o cotidiano escolar. Entretanto, a escola, de um modo geral, não tem gerado estímulos que propiciem aos alunos uma leitura hábil, tampouco permite inferências como intervenções criativas dos alunos enquanto leem. Nesse sentido, o campo de estudos em metacognição surge como um conceito capital para este teste, porque apresenta meios de investigar o saber do aluno em relação ao que 
será exigido na atividade de leitura e ao que induz a sua reflexão sobre esta atividade enquanto a executa.

Como a metacognição é um conceito relacionado à reflexão e à regulação das atividades cognitivas, entendese que atividades orientadas por estratégias metacognitivas permitirão o desenvolvimento de uma leitura hábil, que explore o saber do aluno criativamente. Em busca de explorar e compreender a forma de realização dessas estratégias em leitura, este trabalho apresenta-se sob o modelo de questionário, dividido em dois momentos. $\mathrm{O}$ primeiro momento do teste foi constituído por perguntas de pré-leitura estimuladoras de hipóteses e perguntas de pósleitura que objetivavam recuperar as informações recrutadas pelos alunos em sua leitura. Em um segundo momento, foi solicitado um resumo da história, pois se pretendia recuperar dados da leitura promovida anteriormente e avaliar o nível de compreensão em leitura desses estudantes.

Vale ressaltar que a atividade de pré-leitura constitui fator de suma importância para a compreensão metacognitiva da leitura, porque possibilita ao aluno, como leitor, acessar ao seu conhecimento prévio, ajudando-o a hipotetizar a respeito dos assuntos que serão tratados no texto (RANDI et al., 2005). Em termos metacognitivos, a pré-leitura educa o 
aluno a administrar as estratégias que serão requeridas em direção a uma leitura que ultrapasse o nível literal, de cópia e colagem de informações (APPLEGATE, 2002). Isso ocorre porque essa atividade viabiliza a construção do significado do texto pelo aluno, partindo-se das informações que o aluno possui para alcançar os dados fornecidos pelo texto.

Já as atividades de pós-leitura arrolam a retomada dos fatos tratados na leitura anteriormente desenvolvida, buscando recrutar do aluno as informações construídas em sua leitura. Para tanto, as atividades de sumarização, as questões que requerem dados do texto em conjunto com a avaliação do aluno, bem como as atividades inferenciais que acionam dados do texto para alcance de informações extratextuais, são válidas em termos metacognitivos porque permitem visualizar a leitura como um processo de, simultaneamente, extrair e construir significado através da interação com a linguagem escrita (RANDI et. al, 2005).

Assim, a avaliação da pós-leitura no teste pretende mensurar o nível de leitura desenvolvido pelos alunos, bem como perceber os Modelos Cognitivos Idealizados (MCls), de base cultural, e que elementos desses modelos estão sendo enquadrados na leitura de textos escolares. Percebendo o que os alunos puderam recuperar nesta atividade, é possível 
verificar se há uma confirmação do $\mathrm{MCl}$ presente no texto ou se há um contraste entre o que os alunos perceberam e o que estava exposto no texto. Cabe destacar que, nesse período de produção escrita, eles não possuíam acesso ao texto lido, prontamente recolhido após sua leitura.

O teste foi aplicado por um professor da Rede Pública Municipal de ensino da cidade do Rio de Janeiro, como parte comum à aula de língua portuguesa em sua turma de 6으 ano do ensino fundamental. Participaram do teste 20 alunos matriculados em uma das turmas do referido segmento.

\section{RESULTADOS}

A aplicação do teste permitiu verificar questões interessantes que concernem à atividade de leitura. Percebendo que a coleta de dados deste teste procedeu com felicidade, vale considerar as postulações de Maki \& McGuire (2002), que em seu trabalho afirmam que os estudantes parecem mais motivados a realizar um teste desta natureza em sala de aula do que em outros tipos de ambiente. Além disso, um teste em sala de aula permite a manutenção de certa fidelidade no comportamento do aluno, com o desenvolvimento mais genuíno de uma atividade escolar.

O primeiro momento do teste consistia em perceber o nível de conhecimento prévio que os alunos possuíam em 
relação ao conteúdo do texto a ser lido, intitulado As estações do ano. Havia um texto que relatava o estabelecimento das estações do ano sob o ponto de vista grego, por meio de uma lenda. Acompanhavam o texto inicial perguntas estimuladoras de hipóteses com o intuito de perceber se os alunos eram capazes de estabelecer previsões sobre o assunto a ser lido:

Leitura do Texto

-Antes de ler (Material do livro)

Na antiga Grécia, os gregos acreditavam em muitos deuses. $O$ mais poderoso de todos era Zeus. Apesar de ser casado com a deusa Hera, Zeus teve um filho com uma mulher mortal, a quem deu o nome de Hércules. Hera, enciumada, fez de tudo para tornar a vida de Hércules um verdadeiro inferno.

- Responda (Questões formuladas para o teste):

a) Quais são as estações do ano?

b) O que você conhece sobre o povo grego?

c) O que você acha que pode haver de parecido entre o povo grego e as estações do ano? 
O comportamento de leitura dos alunos neste primeiro momento revelou que, de um modo geral, todos conheciam as estações do ano, com poucos casos de esquecimento de uma ou outra dentre as quatro existentes.

Em relação ao conhecimento sobre o povo grego, a maioria dos alunos demonstrou retomar o pequeno parágrafo introdutório, respondendo a esta pergunta por meio da estratégia de "cópia e colagem" da informação anteriormente dada. Esse tipo de desempenho demonstra a ausência de informações de cunho pessoal, que denotem o acesso ao conhecimento prévio, e isso é, também, proporcionado pelo uso do livro didático, que promove a exploração constante de exercícios de cópia e colagem de informações do texto lido. Isso comprova que, em relação ao assunto dado no texto, os alunos apresentavam, em grande parte, pouco conhecimento prévio.

Há, entretanto, duas respostas que valem destaque. Um aluno, em resposta à questão $b$, confronta os $\mathrm{MCl}$ de religião das culturas brasileira e grega, comparando o regime religioso monoteísta brasileiro com o antigo regime politeísta grego. Outro aluno, em resposta à mesma pergunta, parece debater a temática da mitologia grega, que era divulgada oralmente entre o povo, com tons de crítica. Seguem-se as respostas: 
b) O que você conhece sobre o povo grego?

Aluno 10: Que existiam muitos deuses e que eles não acreditavam em Deus, só nos deuses deles.

Aluno 14: Eu conheço sobre o povo grego que eles acreditavam em tudo o que os outros falavam.

Ainda em relação à primeira parte do teste, em resposta à questão c, grande parte dos alunos não estabeleceu associações entre o povo grego e as estações do ano. Porém, três respostas merecem ser citadas, pois nessas os alunos parecem associar essas informações ou, pelo menos, empreender essa tentativa. Um dos alunos citou o caráter mágico das estações do ano na cultura grega. Já outro aluno aproximou-se da lenda grega de constituição das estações do ano, citando o fato de antes existir somente a estação da primavera. Em uma terceira resposta, um aluno parece relacionar o assunto "estação do ano" à moda de uso do vestuário. Seguem-se as respostas:

c) O que você acha que pode haver de parecido entre o povo grego e as estações do ano?

Aluno 1: Eu acho parecido os deuses e as estações do ano parecidos porque os deuses tinham feitiços igual as estações do ano. 
Aluno 7: Eu acho que nos gregos não existia a estação do ano, só existia a Primavera.

Aluno 10: Por causa das roupas deles que eram de pano parecido com o verão.

Vale dizer que, embora o aluno 10 tenha falhado metacognitivamente ao estabelecer uma associação de ideias distante em relação ao que se requeria na pergunta de pré-leitura, sua resposta demonstra o conhecimento prévio que possuía sobre o assunto. Essas perguntas iniciais, já comentadas, objetivavam não somente angariar dados que demonstrem o conhecimento prévio dos alunos sobre os assuntos relacionados ao texto, mas também estimular a leitura que seria posteriormente desenvolvida.

Ainda em relação ao primeiro momento do teste, mas no período pós-leitura, as questões propostas de verificação da leitura revelaram dados interessantes. A primeira pergunta, questionadora sobre o vocabulário do texto que parecia desconhecido aos alunos, mostrou respostas bastante semelhantes, pois a maioria dos alunos citou os nomes dos deuses presentes no texto e também algumas palavras destacadas na seção vocabulário, como colheitas, subterrâneo, providência e domínios.

A segunda pergunta proposta era a seguinte: "Você consegue, a partir da leitura desse texto, verificar alguma 
coisa que seja diferente dos hábitos ou dos costumes do meio em que você vive?", que apresentou respostas diversas. Apenas dois alunos não responderam, enquanto outros dois responderam "sim". Mais dois alunos responderam negativamente, alegando não saber do que tratava a questão. Dentre as respostas restantes, muitos alunos apresentaram tópicos desconexos em relação ao texto ou à própria pergunta, o que Randi et al (2005) apontam como falha no acesso às pistas contextuais e na construção de inferências para acesso ao conhecimento prévio. Vale dizer que apenas três respostas foram satisfatórias, estabelecendo, de certa forma, distinção entre os $\mathrm{MCl}$ s correspondentes à cultura grega e a brasileira:

Aluno 4: Eles acreditavam em muitos deuses e deusas.

Aluno 9: Eles acreditavam em muitos deuses e deusas.

Aluno 13: Eles acreditavam em muitos deuses.

A pergunta proposta na questão três objetivava verificar a capacidade do aluno em perceber um dado $\mathrm{MCl}$ requerido, induzindo ao caso das relações familiares. Neste caso, os alunos responderam conforme as expectativas do teste, associando o $\mathrm{MCl}$ de família ao sentimento demonstrado 
pela personagem Deméter, uma mãe no texto. Entretanto, alguns alunos que fugiram a essa expectativa relacionaram a pergunta ao $\mathrm{MCl}$ de trabalho. Tanto a questão como as principais respostas seguem abaixo:

3. Por que você acha que Deméter ficou triste com o sumiço de Perséfone?

Aluno 1: Porque Deméter é a mãe de Perséfone e mesmo Deméter sendo uma deusa ela tem sentimento por sua filha e outras pessoas.

Aluno 10: Porque era a filha dela que ela amava.

Aluno 16: Porque ela era sua única filha e ela que fazia as colheitas e se ela não fizesse todos iam morrer de fome.

A questão quatro propunha o seguinte: "Escreva, com suas palavras, sobre o personagem que tem poder para dar vida aos homens e fornecer alimentos". Em grande parte, as respostas não correspondiam ao que se pedia, pois os estudantes não conseguiam acessar as informações fornecidas em sua leitura para construir sua significação sobre a questão, pois apenas citavam o nome de um personagem do texto. Entretanto, vale destacar que, em algumas respostas, houve o cumprimento do comando dado na questão e, em outras, é possível notar a interferência do 
$\mathrm{MCl}$ estabelecido culturalmente para compreensão de outra base cultural acionada pelo texto, a cultura grega.

Ao descrever a respeito do personagem responsável por prover vida e alimentos, os alunos enquadravam sua resposta ao $\mathrm{MCl}$ de religião da cultura brasileira, padrão de crença monoteísta, típico da cultura em que estamos inseridos. Essa ocorrência evidencia um problema metacognitivo na leitura dos alunos, que não conseguem enquadrar sua leitura de acordo com o padrão cultural requerido, o grego. Deste modo, os alunos não manifestam ter monitorado sua leitura, portanto, não estabeleceram conexões válidas a partir do que é acionado pelo texto. Seguem-se os exemplos:

Aluno 3: Sim. Porque se não os homens morrem de fome e desaparecerão.

Aluno 4: É bom porque quando alguém precisa Ele vai estar lá para ajudar.

Aluno 5: Deméter é a deusa dos fornecimento o alimento de homem ela que da os flutos e colheita para todos os homens.

Aluno14: É muito bom porque quando alguém precisar eles nem precisa se preucupar porque Ele já está lá.

A partir dessas respostas fornecidas pelos alunos, podese perceber que, no material didático, há também uma falha 
na exploração do seu conhecimento prévio, porque o texto não fornece dados que permitem aos alunos estabelecerem contraste entre os $\mathrm{MCl}$ de religião das culturas grega e brasileira. Dessa falha estrutural, decorre o problema cognitivo dos alunos falharem no estabelecimento de inferências para a construção do significado em contato com o material didático. Randi et al. (2005) postulam que uma administração eficaz do nível inicial de leitura, uma estratégia metacognitiva, envolve o estabelecimento de inferências, associando-se dados do material lido ao conhecimento prévio do leitor, viabilizando a compreensão em leitura.

Já no segundo momento do teste, em que foi solicitada uma redação com o resumo do texto, pôde-se perceber que determinadas escolhas e associações lexicais apontavam para o $\mathrm{MCl}$ que os alunos acessariam em sua leitura. Um exemplo que destaca este tipo de ocorrência foi a associação, feita por alguns alunos, entre as palavras rapto, presente no texto, e sequestro. Este fato pode ser justificado devido à intensa exibição de reportagens televisivas acerca do assunto, sobretudo no período em que o teste foi aplicado, no último bimestre de 2008, como os seguintes trechos apontam:

Aluno 3: “... um deus das trevas que morava em baixo da terra tinha um subterrâneo seqüestrou uma menina chamada Perséfone". 
Aluno 5: “... o deus das trevas ... se apaixonou pela Perséfone e a sequestrou para o mundo das trevas..."

Aluno 16: "Um dia um deus poderoso chamado Hades saiu do chão e apaixonado por Perséfone seqüestrou ela e a levou para o subterrâneo".

Em algumas redações, bem como nas perguntas pósleitura, percebe-se o acesso ao $\mathrm{MCl}$ de família, tratando das relações entre Deméter, a deusa da colheita, e sua filha Perséfone, que foi raptada pelo deus Hades. Com base nesse dado fornecido pelo texto, os alunos resgatavam sentimentos e fatos que reportavam à questão familiar, possibilitada pelo texto As estações do ano, em que a mãe aparece como uma figura que demonstra preocupação com sua filha e procura zelar pelo seu bem-estar, como comprovam os trechos:

Aluno 4: "Eu me lembro que Hades raptou-se Persefone que sua mãe Demeter ficou desesperada ai as plantas murcharam..."

Aluno 10: “... Percéfone que era muito bonita e que ajudava a mãe dela a fazer plantações (...) um homem chamado Harmes foi e raptou ela e a mãe dela ficou muito preocupada..."

Aluno 15: "Seu pai estava maluco de saudades e sua mãe queria sua filha de volta. (...) E a família ficou feliz para sempre". (grifos meus) 
Este teste permitiu, também, observar o tratamento dado pelos alunos à lenda de criação das estações do ano, uma histórica ficcional. Devido a isso, muitos realçavam o fim do resumo com o clássico "final feliz", típico de certos tipos de contos infantis, o que nos permite postular a presença de interação entre leitor e texto para construção do significado (RANDI, 2005):

Aluno 12: “... quando ele entregou a filha do rei o ficou muito feliz e ficaram felizes para cempre."

Aluno 15: "E a família ficou feliz para sempre!"

Em resumos desenvolvidos por três alunos, foi possível notar que o $\mathrm{MCl}$ relacionado a trabalho ganhou destaque, por influência do próprio texto, que permite a já comentada interação entre leitor, por meio de sua base cultural, e texto. Assim, pode-se considerar que os alunos desenvolveram uma leitura eficaz, construindo o significado associando aspectos do seu conhecimento prévio a dados recrutados do texto, como comprovam os exemplos abaixo:

Aluno 5: "Demeter era deusa das flores plantas e frutos e ela tem uma filha (...) que ajudava na plantação dos homens na colheita..."

Aluno 7: “... e a sua filha tomou a lição 
só fim, na plantação e voltou para casa e botou ela pra trabalhar e ela começou a trabalhar e viveu muito feliz..."

Aluno 10: "Percéfone (...) que ajudava a mãe dela a fazer plantações um dia ela foi fazer plantações, ela e a mãe tinham que fazer plantações se não os povos passavam fome..."

Por fim, vale citar uma ocorrência presente na redação de um dos alunos do teste, em que as escolhas lexicais enaltecem o $\mathrm{MCl}$ de religião, dentro do padrão monoteísta. A redação desse aluno apenas confirma esse fato, pois já nas perguntas exploratórias anteriores à leitura do texto o mesmo destacava em sua escrita essa comparação de $\mathrm{MCls}$. Segue-se o trecho: "Heberta foi e ficou muito feliz do lado de sua filha e a plantação voltou, graças a Deus, porque os homens já estavam morrendo de fome".

Com base nos dados e comentários já citados neste trabalho, pode-se dizer que cada ocorrência, promotora do enriquecimento do teste, revela a tentativa dos alunos em dirigir dois movimentos sobre o texto: recuperar informações acessadas durante a leitura e facilitar o acesso à compreensão do que foi lido. Sendo assim, tanto as associações lexicais quanto a comparação de $\mathrm{MCl}$ permitem a confirmação deste fato. 
A aplicação deste teste possibilitou, ainda, destacar que promover um exercício de leitura orientado por estratégias metacognitivas auxilia o aluno a compreender o texto, produzir significados a partir de concepções autônomas e, portanto, gera estímulos no desenvolvimento desta atividade que ultrapassam o modelo de resposta "cópia e colagem", presente em grande parte dos materiais didáticos. O teste permitiu mostrar que o uso das estratégias metacognitivas foi válido em exercícios de compreensão em leitura, mesmo em um grupo de alunos acostumado aos modelos formatadores presente na maioria dos livros didáticos e divulgados nas atividades escolares.

\section{CONSIDERAÇÕES FINAIS}

Este trabalho se desenvolveu com fins a revelar o crescimento dos estudos em metacognição e a destacar sua importância em atividades escolares, podendo surgir, por exemplo, como uma fonte de informações para professores sobre as habilidades promotoras de uma leitura eficiente.

Este estudo procurou destacar, como em muitos estudos (por exemplo, JOU e SPERB, 2006), a questão da reflexão que o leitor promove durante o processo de compreensão textual, utilizando, sobretudo, estratégias metacognitivas.

A amostragem de um teste composto, essencialmente, 
por táticas metacognitivas em leitura é apenas um exemplo entre tantos outros trabalhos que destacam a importância do desenvolvimento de atividades escolares sob a orientação do monitoramento e controle da própria cognição com fins ao sucesso e aumento da capacidade da aprendizagem. O teste promovido para este trabalho apresentou meios que podem promover a melhoria da atividade de leitura no ambiente escolar, mesmo em turmas com predomínio de estratégias ultrapassadas em leitura, que não geram estímulos em seu fazer. Além disso, o teste demonstrou como o aluno, em plena ação em uma tarefa de leitura, pode construir significados e ser plenamente aproveitado em atividades que considerem seu conhecimento prévio.

O teste revelou, ainda, que falhas em determinadas associações, como a troca do nome de um personagem por outro, que teve razoáveis ocorrências entre os alunos, são comprovações da tentativa dos alunos em recuperar elementos acessados em sua leitura anterior e em processar o material informacional já dado. Os resultados destes estudos possibilitam, também, a construção de um corpo de conhecimento acerca dos mecanismos cognitivos envolvidos no desempenho dos alunos.

A partir dessas informações, professores e estudiosos podem desenvolver situações de aprendizagem que propiciem 
o desenvolvimento de habilidades cognitivas necessárias para promover grande quantidade de informações que são postas em questão ao se tratar de conhecimento dado, processos cognitivos e compreensão em leitura.

\section{REFERÊNCIAS}

Applegate, M. D.; Quinn, K. B.; Applegate, A. J. (2002). Levels of thinking required by comprehension questions in informal reading inventories. In The Reading Teacher. (Vol. 56,2a ed., p. 174-180). New Jersey: Wiley.

Gerhardt, A. F. L. M. (2009). Repensando o certo e o errado: as bases epistêmicas da sócio-cognição na escola. Leitura, Revista da UFAL.

. (2013). Identidades situadas, documentos oficiais e os caminhos abertos para o ensino de língua portuguesa no Brasil. In A. F. L. M. Gerhardt; M. A. de Amorim; A. M. Carvalho. Linguística aplicada e ensino: língua e literatura. Campinas: Pontes/ALAB.

Gerhardt, A. F. L. M.; Botelho, P. F; Amantes, A. M. (2015). Atividades escolares de leitura: uma abordagem cognitiva e metacognitiva. In Revista Brasileira de Linguística Aplicada. Belo Horizonte: Editora UFMG.

Jou, G. I. de; Sperb, T. M. (2006). A Metacognição como Estratégia Reguladora da Aprendizagem. Psicologia: Reflexão e Crítica. (Vol. 19, 2a ed.). Porto Alegre: UFRGS.

Maki, R. H.; McGuire, M. J. (2002). Metacognition for text: implications for education. In T. J. Perfect \& B. L. Schwartz (Eds.). Applied Metacognition. Cambridge: Cambridge University Press.

Griffith, L. P.; Ruan, J. (2005). What is metacognition and what should be its role in literacy instruction. In S. Israel et al. (Eds.). Metacognition in literacy learning. (p. 3-18). London: Lawrence Erlbaum.

Randi, J.; Grigorenko, E.; Sternberg, R. (2005). Revisiting definitions of reading compreehension: Just what is reading comprehension anyway? In S.Israel et al. (Eds.). Metacognition in literacy learning. (p. 19-40). London: Lawrence Erlbaum. 
Schneider, W.; Lockl, K. (2002). The development of metacognitive knowledge in children and adolescents. In T. J. Perfect \& B. L. Schwartz (Eds.). Applied Metacognition. (p. 224-257). Cambridge: University Press.

Tomasello, M.; Racokzy, H. (2003). What makes human cognition unique? From individual toshared to collective intentionality. Mind \& Language. (Vol. 18, 2a ed., p. 121-147). New Jersey: Blackwell Publishing Ltd.

Patricia Ferreira Botelho - Doutora em Língua Portuguesa pela Universidade Federal do Rio de Janeiro (UFRJ) em 2015, onde também concluiu Mestrado em 2010. Desenvolve pesquisa na área de Cognição, Metacognição e ensino, com foco nos estudos em leitura, avaliação de livros didáticos e ensino de língua portuguesa. Docente dos cursos de graduação e pós-graduação no Centro Universitário Geraldo Di Biase (UGB) e no Centro Universitário de Volta Redonda (UNIFOA). Integrante do grupo de pesquisa COGENS - Grupo de Pesquisa em Cognição e Ensino de Línguas. Mais informações em <http://lattes.cnpq. br/9341613087658216>.

Contato: patriciafbufrj@gmail.com 